\title{
Formatos publicitarios en la radio deportiva: de la tradicional cuña publicitaria a la importancia de la figura del animador
}

\author{
Francisco Javier HERRERO GUTIÉRREZ ${ }^{1}$ \\ Universidad de Salamanca \\ Hilario José ROMERO BEJARANO \\ Universidad de Sevilla
}

\begin{abstract}
RESUMEN:
En este artículo se realiza un análisis exploratorio sobre la publicidad en los programas que incluyen retransmisiones deportivas radiofónicas. Por un lado, en el artículo se resalta la importancia que tiene la figura del animador en este género radiofónico, sin olvidar que la tradicional cuña es también un recurso habitual. Por otro lado, se realiza una aproximación para saber qué tipo de anuncio está presente en estos programas. Una metodología basada en técnicas cuantitativas y cualitativas ha permitido obtener unos resultados y conclusiones sobre las que seguir trabajando.
\end{abstract}

PALABRAS CLAVE: radio; radio deportiva; animador radiofónico; comunicación deportiva

TITLE: Advertising formats in sport radio: since the traditional radio spot to the importance of the figure the presenter

\begin{abstract}
In this paper, we realize an exploratory analysis about the advertising in the programs that include sports radio broadcastings. Firstly, the paper highlight the importance of the figure of the presenter in this wireless genre, without forgetting that the traditional radio spot also is an habitual resource. On the other hand, it is realized an approximation to know what type of advertisements appears in these programs. A methodology based on quantitative and qualitative techniques has allowed to obtain a few results and conclusions on which to continue working.
\end{abstract}

KEY WORDS: radio broadcast; sport radio; radio presenter; sport communication.

\section{Introducción}

La publicidad, según la tercera acepción de las definiciones ofrecidas por la Real Academia Española, es la «divulgación de noticias o anuncios de carácter comercial para atraer a posibles compradores, espectadores, usuarios,

1 Personal Investigador en Formación de la Universidad de Salamanca. Realizando la tesis doctoral sobre las retransmisiones deportivas en radio en España, con un proyecto subvencionado y cofinanciado por la Consejería de Educación de la Junta de Castilla y León y el Fondo Social Europeo. E-mail: javiherrero82@usal.es

2 Personal Investigador en Formación de la Universidad de Sevilla. Realizando la tesis doctoral sobre los programas radiofónicos de deportes en España. E-mail: hromero83@hotmail.es $\square$ 
etc.» ${ }^{3}$. La publicidad, por lo tanto, no es solo vender un producto o servicio sino que va más allá y puede tener fines tales como la promoción o el afianzamiento de una marca, entre otros.

A pesar de hacer uso de otros muchos soportes, la publicidad ha encontrado en los medios tradicionales de comunicación, prensa, radio y televisión, una exitosa forma de conseguir sus objetivos. En el momento de crear publicidad para estos medios, cada uno tiene sus propias características. Aparentemente, el que permite una mayor creatividad es el medio televisivo, como consecuencia de su carácter audiovisual que le permite combinar imagen y sonido en un único producto. La prensa basaría su acción persuasiva en la imagen mientras que la radio única y exclusivamente contaría con el factor sonoro. Este artículo se centra en este último medio mencionado: la radio, que tiene la suficiente fuerza como para hacer pensar que «el potencial creativo y la experiencia acumulada de la radio española son demasiado importantes como para desaprovecharlos y ceder el terreno a otras empresas recién llegadas» ${ }^{4}$. Con la palabra, la música, los silencios $-\mathrm{y}$ pausas- y los efectos sonoros y ambientales, el publicista ha de crear el mejor producto posible. Por ello, durante la última década:

Se ha abogado por la innovación y por la experimentación con nuevos formatos que permitan despertar sensaciones y emociones en el radioyente, por la ruptura con las fórmulas más tradicionales y conservadoras de emisión publicitaria radiofónica y por la familiarización con los códigos expresivos del lenguaje radiofónico 5 .

La imaginación a la hora de crear anuncios es un factor fundamental y la competencia por establecer productos realmente persuasivos que lleguen al receptor es una tarea nada sencilla. Afirmación aplicable a cualquier medio y, obviamente, también al radiofónico. La presente investigación, centrada en el medio radiofónico, pretende estudiar la aplicación publicitaria en un género muy específico: las retransmisiones deportivas. La elección de tal género se debe especialmente a los elevados datos de audiencia de estos programas, como demuestra periódicamente el Estudio General de Medios (EGM). Estos datos indican que los programas deportivos están entre los espacios radiofónicos más escuchados de la radio española. Para ejemplificar dicha idea, se exponen los datos correspondientes a las tres olea-

3 Disponible en: http://buscon.rae.es/draeI/SrvltConsulta?TIPO_BUS=3\&LEMA=publicidad $\square$

4 BONET, M. (2005): «La radio española 1994 - 2004. Una década de consolidación y desencanto», Sphera Pública, $\mathrm{n}^{\circ}$ 5. Disponible en Internet:

https://docs.google.com/viewer?url=http://www.ucam.edu/sphera/numeros/numero-5/sphera5.pdf, 68

5 Perona, J. J. y BARBeito, M. L. (2008): «El lenguaje radiofónico en la publicidad del prime time. Los anuncios en la "radio de las estrellas"». Telos: Cuadernos de Comunicación e Innovación, 77, 115-124. Disponible en:

http://sociedadinformacion.fundacion.telefonica.com/telos/articulodocumento.asp@idarticulo\%3D1\&rev\% 3D77.htm. 
das de 2010 (Tabla 1). Además, a partir de esos datos llama la atención que este tipo de programas, a diferencia de lo que ocurre con la mayoría de espacios radiofónicos, lleve ya varias décadas dotando de un gran protagonismo a un formato publicitario que no es la cuña.

Tabla 1: Comparación de las tres oleadas del EGM de 2010

\begin{tabular}{|c|c|c|c|c|c|}
\hline & & & $\begin{array}{c}1^{\mathrm{a}} \text { oleada } \\
\text { EGM }\end{array}$ & $\begin{array}{c}2^{\mathrm{a}} \text { oleada } \\
\text { EGM }\end{array}$ & $\begin{array}{c}3^{\mathrm{a}} \text { oleada } \\
\text { EGM }\end{array}$ \\
\hline \multirow{3}{*}{$\begin{array}{l}\text { Cadena } \\
\text { SER }\end{array}$} & El Larguero & $\begin{array}{l}\text { Lunes a } \\
\text { Viernes }\end{array}$ & 1.261 .000 & 1.363 .000 & 1.035 .000 \\
\hline & \multirow{2}{*}{ Carrusel Deportivo } & Sábados & 1.978 .000 & 1.759 .000 & 1.567 .000 \\
\hline & & Domingos & 2.284 .000 & 1.953 .000 & 1.718 .000 \\
\hline \multirow{4}{*}{$\begin{array}{l}\text { Onda } \\
\text { Cero }\end{array}$} & & Lunes a & & & \\
\hline & ATrtmLE TOque & Viernes & 339.000 & 200.000 & 535.000 \\
\hline & \multirow{2}{*}{ Radioestadio } & Sábados & 396.000 & 290.000 & 583.000 \\
\hline & & Domingos & 517.000. & 557.000 & 664.000 \\
\hline \multirow{4}{*}{$\begin{array}{l}\text { Cadena } \\
\text { COPE }\end{array}$} & El Tirachinas & \multirow{2}{*}{$\begin{array}{l}\text { Lunes a } \\
\text { Viernes }\end{array}$} & 236.000 & 299.000 & \\
\hline & El Partido de las 12 & & & & 439.000 \\
\hline & \multirow{2}{*}{ Tiempo de Juego } & Sábados & 552.000 & 398.000 & 861.000 \\
\hline & & Domingos & 356.000 & 418.000 & 919.000 \\
\hline \multirow{3}{*}{$\begin{array}{c}\text { Radio } \\
\text { Nacional } \\
\text { de Espa- } \\
\text { ña } \\
\text { (RNE) }\end{array}$} & Radiogaceta de los & Lunes a & 154.000 & 169.000 & \\
\hline & \multirow{2}{*}{ Tablero Deportivo } & Sábados & 289.000 & 503.000 & \\
\hline & & Domingos & 270.000 & 320.000 & 289.000 \\
\hline & & & & & \\
\hline \multirow{3}{*}{$\begin{array}{l}\text { Punto } \\
\text { Radio }\end{array}$} & El Mirador & $\begin{array}{l}\text { Lunes a } \\
\text { Viernes }\end{array}$ & 56.000 & 63.000 & 42.000 \\
\hline & \multirow{2}{*}{$\begin{array}{c}\text { El Mirador de la } \\
\text { Liga }\end{array}$} & Sábados & 104.000 & 46.000 & 90.000 \\
\hline & & Domingos & 107.000 & 86.000 & 104.000 \\
\hline
\end{tabular}

Fuente: Datos AIMC.

En la tabla anterior se recogen los programas deportivos más escuchados, contengan o no retransmisiones deportivas -más adelante, se acotará el objeto de estudio. Estos datos no hacen sino corroborar que el deportivo es un género radiofónico que está al alza. De ahí que la facturación publicitaria de dichos espacios deportivos sea una

6 Aunque se entienda que RNE no contiene publicidad, esta emisora forma parte de este estudio en tanto en cuando utiliza la autopromoción. 
de las más elevadas en la radio española. Sirva como ejemplo el programa «Carrusel Deportivo», que siempre fue «una enorme fuente de ingresos para la Cadena SER a través de la gran cantidad de cuñas publicitarias y espacios patrocinados que ha tenido. Para ello a lo largo de sus casi ya cincuenta años de existencia ha tenido nombres muy relevantes en esta tarea $\rangle^{7}$. Dejando al margen los principales programas nocturnos que generalmente se emiten en la medianoche y cuya publicidad está basada en la cuña, aunque está situación parece estar cambiando últimamente-, el género de las retransmisiones deportivas radiofónicas ha ido creando una forma "particular» de vender publicidad con el paso de los años. Asimismo, en dicho género se han forjado los mejores animadores radiofónicos españoles. No obstante, la tradicional cuña publicitaria también está presente en el mismo.

\section{Marco teórico}

Para tratar de englobar el objeto de estudio dentro de un marco teórico, en la presente sección se presentarán algunas nociones básicas, pero esenciales, que se deberían tener en cuenta. Por un lado, la importancia de la publicidad en radio y las características que definen y diferencian la presentación de ésta con respecto a otros medios, como la televisión o la prensa escrita. En segundo lugar, y tras partir de un marco más general, se tratará de hacer hincapié sobre los programas deportivos radiofónicos y, en particular, sobre las retransmisiones deportivas en la radio española. Por último, se ofrece una panorámica muy general sobre la importancia de fusionar publicidad e información en un único discurso.

\subsection{Publicidad en radio: de lo general a lo particular}

Si para ciertos autores la publicidad en radio debe limitarse a vender productos y marcas comerciales, para otros este concepto va más allá hasta el punto de ser considerado como un género radiofónico en sí mismo. En esta línea, Ortiz y Volpini consideran que «la publicidad, que siempre ha tenido un papel relevante y trascendental en el servicio a la radio, se asemeja al resto de los productos radiofónicos, que asimismo gozan de una peculiaridad exclusiva y diferente a los modelos comunicativos utilizados en otros medios ${ }^{8}$. Con respecto a esta última perspectiva, los mensajes publicitarios forman parte del discurso radiofónico, contribuyendo a configurar la imagen que los oyentes perciben acerca de las diferentes emisoras. Según Rodero, los anuncios de buena o mala calidad afectan de igual forma a la percepción de la audiencia, ya que Marca, 49.

Malvar, L. (2005): La radio deportiva en España: 1927-2000, Madrid, Pearson Alhambra y

8 ORTIZ, M. A. Y VolPINI, F. (1995): Diseño de programas en radio: guiones, géneros y fórmulas. Barcelona, Paidós Ibérica, 15. 
ésta «en todo momento está escuchando radio. Todo el conjunto forma parte de su escucha radiofónica, de su consumo del medio»» 9

La radio, pese a la ausencia del enorme impacto visual de la imagen y las multitudinarias audiencias del medio televisivo, se proyecta como un soporte de gran atractivo para los anunciantes. En primer lugar, hay que subrayar las numerosas posibilidades creativas que traen consigo los cuatro componentes fundamentales del lenguaje radiofónico, especialmente para un sector como el publicitario cuyo propósito principal es la persuasión emocional de sus respectivos públicos objetivos: voz (auténtico artífice para conseguir el impacto dramático deseado por la publicidad), música, efectos sonoros y silencio. A ello se añade la intensa fidelidad existente entre los oyentes y el medio radiofónico (a diferencia de lo que ocurre en televisión), así como el carácter personal e íntimo que caracteriza a este tipo de comunicación y que favorece la identificación de la audiencia con los contenidos emitidos. Otro aspecto de cierta relevancia es, por ejemplo, la gran credibilidad que proyecta la radio en la sociedad, lo que fomenta a su vez la confianza de los anunciantes a la hora de informar acerca de sus productos en dicho medio.

No obstante, ni la integración del mensaje publicitario como elemento del discurso radiofónico ha gozado del protagonismo que merece, ni los numerosos elementos que favorecen la unión entre radio y publicidad han conseguido atraer la inversión esperada de los anunciantes. Tal y como afirman Perona y Barbeito, el fenómeno publicitario radiofónico durante los primeros años del siglo XXI se define por su carácter inmovilista y por la ausencia de la explotación de la gran mayoría de recursos del medio, «apostando por mensajes que no potencian la fantasía ni la imaginación, y que venden el producto desde la realidad, sin recurrir a la seducción ni a la activación de los sentidos» ${ }^{10}$.

Ello se debe por un lado, al uso secundario que las empresas hacen de la publicidad radiofónica. Gran parte de estos anuncios se limitan a informar de aquellos datos que no aparecen en los spots televisivos, como consecuencia de la desconfianza que genera la ausencia de imagen visual y del desconocimiento de las posibilidades que trae consigo la imagen sonora de los productos. Por otro lado, este conservadurismo se debe a la homogeneización que ha caracterizado las parrillas de programación de las principales cadenas generalistas durante las tres últimas décadas. De hecho, la radio se erige como un medio eminentemente informativo, lo que ha provocado según Balsebre un fuerte distanciamiento con la publicidad ${ }^{11}$.

Mientras que la información sigue siendo la base de dichos anuncios, la cuña se ha consolidado como el formato más utilizado en este medio (mensajes pregrabados de entre veinte y treinta segundos que se emiten de forma intercalada en la

9 Rodero, E. (2008): «Publicidad en radio: Publicidad, sí, pero no radiofónica«»», Área Abierta, 20, julio de 2008. Disponible en Internet:

http://revistas.ucm.es/inf/15788393/articulos/ARAB0808230001E.PDF, 6.

10 Perona, J. J. y BARBeito, M. L. (2008), op. cit.

11 BALSEBRE, A. (1994): El lenguaje radiofónico, Madrid, Cátedra. 
programación). Asimismo, existe otro tipo de mensajes que desde hace ya algunas décadas forman parte de un gran número de programas radiofónicos. Es el caso de la mención, también denominada publicidad in voce o prescripción, y que se refiere a las inserciones que de manera aparentemente espontánea introduce el locutor dentro de su propio parlamento. Como afirma Guarinos, estos mensajes apenas se distinguen «de la conversación que está manteniendo o de la descripción de la jugada que se está produciendo en el campo de fútbol» ${ }^{12}$.

Estos recursos publicitarios son muy utilizados en los magacines de actualidad, así como en los programas de deportes y, especialmente, en las retransmisiones en directo de eventos futbolísticos. Se trata, pues, de explotar el prestigio y la gran credibilidad que generan los locutores estrella del país. Debido a la competencia existente en el panorama radiofónico, con programaciones que coinciden en horarios y contenidos en la mayoría de emisoras generalistas, estos profesionales juegan cada vez un papel más importante como prescriptores en la sociedad con un alto poder de sugestión.

\subsection{La publicidad en las retransmisiones deportivas radiofónicas}

Como se ha indicado, más que en la radio deportiva de forma general, lo que en este artículo se pretende estudiar es la visión de la publicidad radiofónica en los programas que contienen retransmisiones deportivas, de cuyo contexto histórico se pueden resaltar distintos aspectos:

a) el género de las retransmisiones futbolísticas nace como plataforma de proyección de la radio en cadena: la famosa rueda de locutores: «La estructura que patrocinará finalmente esta promoción del fútbol será la radiodifusión en cadena que ponen en marcha las distintas empresas radiofónicas en el periodo 1952$1955 »^{13}$.

b) este género es un reclamo para los grandes anunciantes transnacionales que empiezan a llegar a España tras los acuerdos hispano-norteamericanos de 1953.

c) habitualmente las retransmisiones deportivas radiofónicas han sido un reclamo de la audiencia masculina que la radio todavía no tenía: «El fútbol será la flauta de Hamelin que captará y seducirá mágicamente a una masiva audiencia masculina» ${ }^{14}$.

d) este género, en sus comienzos, estuvo al servicio de la publicidad de bebidas alcohólicas: «Carrusel Deportivo» nace en octubre de 1952 como «Carrusel Deportivo Terry».

12 GuARINOS, V. (2000): «Géneros publicitarios y radiofónicos: últimas tendencias», Questiones Publicitarias, 8, 26-35. Disponible en Internet:

http://www.maecei.es/pdf/n8/articulos/generos_publicitarios_radiofonicos_ultimas_tendencias.pdf, 29.

13 BALSEBre, A. (2002): Historia de la radio en España (v. II), Madrid, Cátedra, 327.

14 Ibídem, 336. 
d) las retransmisiones deportivas radiofónicas han ayudado a las estrategias de transformación de la radio en un medio popular de masas, que seguramente vino ayudado porque el transistor «desplaza» la audición radiofónica del hogar al exterior o por la individualización de la escucha ${ }^{15}$.

Las retransmisiones deportivas tradicionalmente han tenido un formato carrusel, que ha existido desde mediados del siglo XX. Por «carrusel» se entiende:

Un programa deportivo, basado en la retransmisión, en el que se realizan conexiones constantes con diversas pruebas deportivas que se están disputando al mismo tiempo pero en espacios geográficos diferentes. Se informa, principalmente, del minuto de juego y del resultado pero también muchos de los minutos del programa están destinados a la retransmisión de qué sucede en dicha prueba deportiva ${ }^{16}$.

Esta acotación se debe a que los principales programas nocturnos y sus formatos publicitarios se han basado fundamentalmente en la simple cuña publicitaria -algo que, sin embargo, parece estar variando en la actualidad. En cambio, los programas de retransmisiones deportivas radiofónicas han sido un género que ha creado su propia forma de crear publicidad:

El formato de las retransmisiones futbolísticas, que ha tenido como modelos fundacionales las emisiones del «Carrusel Deportivo» (Cadena SER) y «Tablero Deportivo» (RNE), ha sido tradicionalmente uno de los formatos radiofónicos más comerciales, que nace precisamente en la década de los años 50 cuando la radio profesionaliza sus redes comerciales y consigue los primeros grandes anunciantes ${ }^{17}$.

Con el paso de los años, «Carrusel Deportivo» ha sido el referente en la creación de la publicidad radiofónica. El histórico espacio deportivo de la cadena SER ha sabido conjugar a la perfección publicidad e información, a través de un programa estructurado en torno a las retransmisiones futbolísticas mediante el ya mencionado modo carrusel. «Carrusel Deportivo» se ha ido haciendo célebre por innovar con nuevas secciones que se han ido convirtiendo en históricas ${ }^{18}$. Con esta combinación de información y publicidad, este programa puede ser considerado como un referente no solo en la radio deportiva sino también en toda la radio española gracias especialmente a sus grandes «vendedores»:

15 Ibídem, 335-336.

16 Herrero GutiérReZ, F. J. y Rodríguez RAMOS, D. (2009): «La locución de los narradores deportivos radiofónicos en España«»), Revista Latina de Comunicación Social, 64, 968-987, La Laguna (Tenerife), Universidad de La Laguna, recuperado el 4 de octubre de 2010 de http://www.revistalatinacs.org/09/art/874_Salamanca/75_101_Herrero.html DOI: 10.4185/RLCS-64-2009874-968-987.

17 Balsebre, A.; Ricarte, J. M.; Perona, J. J.; Roca, D.; BARBeito, M. L.; FAJUla, A. (2006): Los mitos de la publicidad radiofónica. Estrategias de la comunicación publicitaria en la radio española, Madrid, Cátedra, 147.

18 Malvar, L. (2005), op. cit., 48-56. 
El formato radiofónico de «Carrusel Deportivo» ha tenido siempre como comunicadores y hombres-anuncio a grandes locutores-estrella, que sabían vender muy bien el producto y constituían un buen reclamo de anunciantes. Juan de Toro, Joaquín Prat, José M ${ }^{a}$ García y Pepe Domingo Castaño han sido o son locutores-estrella de gran credibilidad para el sector publicitario ${ }^{19}$.

Pero «Carrusel Deportivo» no es el único programa que juega con esta figura del animador. Sin embargo, Pepe Domingo Castaño sí es uno de los principales animadores de la actual radio deportiva. Al respecto, Rodero afirma que este animador «es un claro exponente de las posibilidades que ofrece la voz en la radio, además de la posibilidad de encontrar nuevas fórmulas eficaces de hacer llegar la publicidad al consumidor integrándola en el programa donde se inserta» ${ }^{20}$. Gabilondo dice sobre el propio Pepe Domingo Castaño: «Nunca fueron la radio ni la publicidad mejor servidos» ${ }^{21}$.

No obstante, hay que reseñar que la marcha de Paco González -director de «Carrusel Deportivo» desde septiembre de $1992^{22}$ hasta mayo de 2010- también conllevó la salida de Pepe Domingo Castaño, que siguió el mismo camino que Paco González, al irse de la SER a la COPE. Pepe Domingo Castaño estuvo en la cadena SER desde enero de $1987^{23}$ hasta julio de 2010. Los animadores de mayor prestigio han pasado por los estudios de la SER desde los primeros tiempos del programa «Carrusel Deportivo»:

Vicente Marco tuvo a su lado dos grandes y fieles compañeros de faena como fueron Juan de Toro y Pepe Bermejo. Sin olvidarnos del encargado de rematar los resultados con esa publicidad tan entrañable e inolvidable de « ¡Coñac Decano! ¡Caballero, qué Coñac!», a la cual ponía la voz en «Carrusel» Manolo Serrano ${ }^{24}$.

A continuación siguieron otros nombres como Joaquín Prats, el mencionado Juan de Toro, Juan Vives o creativos como Alfonso Morata y Paco Marqués; más efímero fue el paso de Andrés Caparrós ${ }^{25}$. Los primeros anuncios eran previamente montados en un estudio de grabación ${ }^{26}$ aunque los avances tecnológicos han ido permitiendo que hoy en día se hagan en directo, a viva voz, e incluyendo sonidos más allá de la propia palabra. Analizar esos formatos es lo que se pretende con este artículo.

\section{Ibidem, 147.}

20 RODERO, E. (2008), op. cit., 14.

21 Gabilondo, I., en CASTAÑo, P. D. (2006): Carrusel Deportivo: diario de un año, Madrid, Santillana Ediciones Generales, 14.

22 MALVAR, L. (2005), op. cit., 70.

23 Ibídem, 70.

24 Ibídem, 49.

25 Ibídem, 49-51.

26 Ibídem, 49. 
Además, en líneas generales, los programas tipo «carrusel» son programas que vienen marcados publicitariamente por una estructura que contiene distintos espacios y cuyas inserciones publicitarias son determinadas tanto por las franjas horarias como por los espacios que en éstas se produzcan. Según unos u otros espacios, se puede justificar el empleo de unos determinados formatos publicitarios y una determinada tipología concreta de anunciantes o productos, vinculada no únicamente a los cambios legislativos, aunque también a éstos.

\subsection{La importancia de un discurso que no diferencie información y publicidad}

Las retransmisiones deportivas en directo basan su estrategia en informar sobre lo que acontece en cada evento, al tiempo que en conseguir emocionar y entretener a la audiencia. Así, la espontaneidad y expresividad se convierten en dos pilares esenciales del discurso en este tipo de espacios, con el objetivo según Castañón, de «regular la emoción con el mejor uso posible del lenguaje, desarrollar su capacidad para crear imágenes mentales y captar la atención con voces prodigiosas y libres juegos de asociaciones» ${ }^{27}$.

Todo ello mediante el despliegue de un amplio número de recursos léxicos y fónicos. Sirven de ejemplo, en cuanto a la fonoestilística se refiere, el especial cuidado de la vocalización, el uso de un elevado número de palabras en pequeños espacios de tiempo o los efectos y juegos de ritmo y entonación, entre otros.

En esta línea, el discurso pronunciado en estos programas puede llegar a influir sobre otros contenidos emitidos en los mismos, ya que, como afirma Betés, «sus códigos y sus ritmos, veloces pero impactantes, han contagiado al resto de conteni$\operatorname{dos} »^{28}$. En el caso de la publicidad radiofónica, la relación emocional que el medio mantiene con su público en estos espacios se puede utilizar como estrategia persuasiva para impactar más efectivamente en la mente del oyente.

Y al mismo tiempo, el discurso publicitario puede contribuir a desarrollar y reciclar esos códigos y ritmos a los que alude Betés. En este contexto, Castañón ha analizado la presencia de figuras clave en la historia de las retransmisiones de la radio española, que han trasladado los rasgos más característicos de sus locuciones a la emisión de anuncios publicitarios:

Esta interpretación se ha extendido a la animación publicitaria que integra la publicidad en los contenidos radiofónicos, en un trabajo intergeneracional de constante esfuerzo y afán de superación que han desarrollado, entre otros, Vicente Marco, José Luis Pécker, Juan Toro o Joaquín Prat. Y que entre ascenso de puerto, carrera de ve-

27 CASTAÑÓN RODRÍGUEZ, J. (2009): «Recursos lingüísticos en la radio deportiva», Idioma y deporte [en línea], 108. Disponible en Internet: http://www.idiomaydeporte.com/radiorec.htm ISSN: 1578-7281, 34.

28 GonZÁLEZ CONDE, J. (2008): «La publicidad como género radiofónico», en Alcudia, M. (coord.): Nuevas perspectivas sobre los géneros radiofónicos, Madrid, Fragua, 155 (148-191). 
locidad, triple baloncestístico o coronación de un ocho mil siguen la fiesta social de la comunicación degustando un jamón único en el mundo o una bolsa de pipas de las que hicieron hablar al toro al morir ${ }^{29}$.

Por un lado, se consigue potenciar las marcas o productos de una forma más eficaz, natural e improvisada, fruto de la emoción que caracteriza de principio a fin las retransmisiones deportivas en directo; más si cabe, se tiene en cuenta la extraordinaria capacidad de influencia que posee el deporte en la sociedad en general.

Y por otro, la publicidad colabora con los objetivos del programa, transmitiendo una gran diversidad de sensaciones de acuerdo a lo que acontece en cada momento en los respectivos eventos. Como ejemplo, el narrador puede hacer uso de un tono de voz más elevado y una mayor velocidad de locución al mencionar las características de un producto determinado, con el objetivo de animar a la audiencia cuando el resultado no es favorable. Al respecto, el primer director de «Carrusel deportivo», Vicente Marco, ha afirmado que «la publicidad siempre estuvo ligada al fútbol, incluso creando un estilo que proporciona un estado de ánimo importante al oyente» ${ }^{30}$.

\subsubsection{La figura del animador}

Tomando como referencia lo anteriormente mencionado, se hace necesario destacar la figura del animador. El rol de dicha figura es animar las narraciones y comentarios del resto de locutores y colaboradores, a través fundamentalmente de la introducción de mensajes publicitarios. Para realizar dichos anuncios, el animador ha de utilizar tanto los aspectos verbales -el nivel discursivo- como las cualidades sonoras y el manejo de estas -timbre, tono, intensidad-, pues un anuncio es transmitido de una $u$ otra forma dependiendo del momento del programa. A modo de ejemplo, no es lo mismo emitir publicidad durante una jugada intrascendente del partido que justo después de un gol.

\section{Objetivos e hipótesis}

Los objetivos marcados en este artículo giran en torno al estudio de la publicidad radiofónica que está presente en el género de las retransmisiones deportivas españolas. El objetivo principal es comprobar si los principales programas deportivos con retransmisiones deportivas en la radio española cuentan o no con la figura del animador. A partir de ello, se analizará qué tipos de anuncio emplean: con animador, sin animador, cuña publicitaria, etc.

\footnotetext{
29 CASTAÑón RodRÍGUEZ, J. (2009), op. cit., 5.

30 RuIZ YudEGo, M. (2002): «Análisis de la comunicación deportiva en radio a través de un programa pionero: Carrusel Deportivo», Proyecto de licenciatura, Universidad Pontificia de Salamanca, 98.
} 
Al analizar un número determinado de programas -con un mínimo de horas- se puede indagar también sobre qué tipos de anuncios existen y la función u objetivo de éstos: mera publicidad, autopromoción, cuasi-autopromoción. Para alcanzar todo ello se parte de una serie de hipótesis:

1) La figura del animador está presente en los principales programas deportivos radiofónicos.

2) A diferencia de otros programas radiofónicos, el mayor porcentaje de los anuncios publicitarios en este género radiofónico tiene como base la figura del animador y deja en un segundo plano la cuña publicitaria. Ésta última, a su vez, es el formato publicitario más usado para los anuncios grabados.

3) Los principales anuncios de la radio deportiva española tienen como principal función vender un producto o servicio ajeno a la emisora radiofónica.

\section{Metodología}

La metodología estará basada en la escucha repetida -a través de la grabaciónde varios programas deportivos de la radio española -que contenga retransmisiones- durante los meses de agosto, septiembre y octubre del año 2010, coincidiendo con el comienzo de la temporada radiofónica (2010/11). Por un lado, se analizaran cualitativamente algunos ítems, como aquéllos que hacen referencia a los siguientes aspectos:

- si existe figura del animador

- saber interpretar qué tipos de anuncios existen (formatos)

Para realizar la presente investigación se ha contado con dos codificadores, número que se considera suficiente ${ }^{31}$ a tenor del estudio que se plantea. Para llegar a los resultados y de forma previa al proceso de evaluación, sea producido un acuerdo inter-codificadores a través del cual se han puesto en común distintos conceptos tales como qué se entiende por animador, marcar claramente qué son los determinados formatos publicitarios -según los principales manuales sobre radio- o hacer una distinción entre los diferentes elementos que pueden entrar a formar parte de un anuncio publicitario radiofónico.

Evidentemente, las técnicas cuantitativas también han estado presentes en la investigación. Cuantitativamente, y una vez superado el paso inicial cualitativo, se han podido contar los tipos de anuncio por su forma: cuña, mención, con presencia del animador, etc. En definitiva, se ha trabajado con un híbrido entre ambas técnicas. Y todo ello a partir de la siguiente ficha de análisis (Tablas 2 y 3):

31 Igartua, J. J. (2006): Métodos cuantitativos de investigación en comunicación, Barcelona, Bosch, 14. 
Tabla 2: Ficha de análisis (parte 1/2).

\begin{tabular}{|r|r|r|r|r|r|r|}
\hline Emisora & Programa & Fecha & $\begin{array}{r}\text { Hora } \\
\text { analizada }\end{array}$ & $\begin{array}{r}\text { Número } \\
\text { de minutos } \\
\text { analizados }\end{array}$ & $\begin{array}{r}\text { iExiste } \\
\text { figura del } \\
\text { animador? }\end{array}$ & Nombre \\
\hline
\end{tabular}

Fuente: Elaboración propia.

Tabla 3: Ficha de análisis (parte 2/2).

\begin{tabular}{|c|c|c|c|c|}
\hline Anunciante & $\begin{array}{c}\text { ¿Quién } \\
\text { realiza el } \\
\text { anuncio? }\end{array}$ & $\begin{array}{c}\text { ¿Participa } \\
\text { alguna otra } \\
\text { persona? ¿So- } \\
\text { nidos? }\end{array}$ & $\begin{array}{c}\text { Tipo de anun- } \\
\text { cio }\end{array}$ & Objetivo del anuncio \\
\hline
\end{tabular}

Fuente: Elaboración propia.

Para realizar este estudio, se tomaron como referencia las cinco emisoras más escuchadas que abarcan una mayor parte del territorio español en su sistema de emisión analógica (que estén presentes en, al menos, tres comunidades autónomas). Para ello se acudió al EGM (Estudio General de Medios) y el último resumen disponible (abril de 2009 a marzo de 2010). Según este estudio, las cinco emisoras generalistas más escuchadas son: la cadena SER, Onda Cero, la cadena COPE, Radio Nacional de España y Punto Radio. Aparte de las cuatro emisoras privadas seleccionadas, también se cree conveniente incluir Radio Nacional de España, porque se parte de la idea de que en dicha emisora existe un tipo de publicidad concreto: «La publicidad que realiza la emisora sobre sí misma y que trasciende el mismo marco de lo publicitario, pues no se circunscribe a actuaciones puntuales sino que impregna todo el espacio radiofónico: la continuidad $\rangle^{32}$. Extraídos del conjunto de la programación los programas de retransmisiones deportivas, estos son los siguientes (Tabla 4):

Tabla 4: Programas seleccionados.

\begin{tabular}{|c|c|c|c|c|}
\hline Cadena SER & Onda Cero & Cadena COPE & $\begin{array}{c}\text { Radio Nacional } \\
\text { de España }\end{array}$ & Punto Radio \\
\hline $\begin{array}{c}\text { Carrusel Depor- } \\
\text { tivo }\end{array}$ & Radioestadio & $\begin{array}{c}\text { Tiempo de } \\
\text { Juego }\end{array}$ & $\begin{array}{c}\text { Tablero Depor- } \\
\text { tivo }\end{array}$ & $\begin{array}{c}\text { El Mirador de } \\
\text { la Liga }\end{array}$ \\
\hline
\end{tabular}

Fuente: Elaboración propia.

La muestra extraida es no probabilística. Y de las dos técnicas no probabilísticas que proponen Riffe, Lacy y Fico ${ }^{33}$, este estudio se basa en la de conveniencia. De acuerdo

32 Rodero, E., AlOnSo, C. M. y FuENTES, J. A. (2004): La radio que convence. Manual para creativos y locutores publicitarios, Barcelona, Editorial Ariel, 55.

33 RIFFE, D.; LACY, S.; FICO, F. G. (1998): Analyzing media messages: using quantitative content analysis in research. Mahwah (New Jersey), Lawrence Erlbaum, 84. 
con estos autores, la validez de la investigación está asegurada conforme la muestra seleccionada cumpla unas determinados condiciones, que son específicamente tres:

1) En primer lugar, «the material being studied must be difficult to obtain» 34 . Evidentemente, las modernas técnicas de hoy en día permiten realizar grabaciones de programas radiofónicos, pero el inconveniente está presente desde el momento en que no sería sencillo obtener grabaciones de años atrás, algo que en teoría tampoco ha de preocupar pues lo que se pretende es examinar el panorama actual.

2) En segundo lugar, «resources limit the ability to generate a random sample of the population ${ }^{35}$; razón que también se produce como consecuencia de que no existe un censo real de todo el material que sería objeto de análisis; entre otras razones, por estar en constante aumento día a día.

3) Por último, la principal validez de la investigación viene dada porque «a researcher is exploring some underresearched but important area ${ }^{36}$. En este sentido, el estudio se realiza porque es un área poco investigada pero que tiene una trascendencia bastante grande. Al ser una investigación de carácter exploratorio, puede dar paso a futuros estudios más completos en los que sí se pueda emplear una muestra probabilística, aunque sea para un determinado periodo de tiempo; por ejemplo: primera década del siglo XXI.

\section{Resultados}

Los resultados obtenidos están presentados en la siguiente tabla - resumen (Tabla 5) y posteriormente diseminados en el apartado de discusión de resultados. Para comenzar, hay que señalar que se ha analizado un total de 515 minutos distribuidos de la siguiente manera (Tabla 6):

Tabla 5: Tabla - resumen de resultados (1/2).

\begin{tabular}{|c|c|c|}
\hline Programa & Emisora & Horas y minutos analizados \\
\hline Carrusel Deportivo & Cadena SER & 1 hora y 59 minutos \\
\hline Tiempo de Juego & Cadena COPE & 1 hora y 58 minutos \\
\hline Radioestadio & Onda Cero & 1 hora y 48 minutos \\
\hline El Mirador de la Liga & Punto Radio & 1 hora y 40 minutos \\
\hline Tablero Deportivo & Radio Nacional de España & 1 hora y 10 minutos \\
\hline \multicolumn{2}{|c|}{ TOTAL } & 8 horas y 35 minutos \\
\hline
\end{tabular}

Fuente: Elaboración propia.

\footnotetext{
34 Ibídem, 85.

35 Ibídem, 85 .

36 Ibídem, 85 .
} 
Tabla 6: Tabla - resumen de resultados (2/2).

\begin{tabular}{|c|c|c|c|c|c|c|}
\hline & Emisora & Programa & Fecha & $\begin{array}{l}\text { Hora } \\
\text { analizada }\end{array}$ & $\begin{array}{l}\text { Minutos } \\
\text { analizados }\end{array}$ & $\begin{array}{l}\text { Nombre del ani- } \\
\text { mador (en caso de } \\
\text { que exista) }\end{array}$ \\
\hline 1 & $\begin{array}{l}\text { Punto } \\
\text { Radio }\end{array}$ & $\begin{array}{l}\text { El Mirador de } \\
\text { la Liga }\end{array}$ & $28-8-2010$ & $\begin{array}{l}18.30- \\
19.00\end{array}$ & 30 & $\begin{array}{l}\text { Fernando Martínez } \\
\text { Teruel } \\
\text { «Fernandisco» }\end{array}$ \\
\hline 2 & $\begin{array}{l}\text { Onda } \\
\text { Cero }\end{array}$ & Radioestadio & $28-8-2010$ & $\begin{array}{l}18: 27- \\
19: 00\end{array}$ & 33 & $\begin{array}{l}\text { Javier Ruiz Taboa- } \\
\text { da }\end{array}$ \\
\hline 3 & $\begin{array}{l}\text { Cadena } \\
\text { SER }\end{array}$ & $\begin{array}{l}\text { Carrusel De- } \\
\text { portivo }\end{array}$ & $29-8-2010$ & $\begin{array}{l}16.15- \\
16.52\end{array}$ & 37 & Juanma Ortega \\
\hline 4 & $\begin{array}{l}\text { Punto } \\
\text { Radio }\end{array}$ & $\begin{array}{l}\text { El Mirador de } \\
\text { la Liga }\end{array}$ & $29-8-2010$ & $\begin{array}{l}17.40- \\
18: 05\end{array}$ & 25 & $\begin{array}{l}\text { Fernando Martínez } \\
\text { Teruel «Fernandis- } \\
\text { co» }\end{array}$ \\
\hline 5 & $\begin{array}{l}\text { Onda } \\
\text { Cero }\end{array}$ & Radioestadio & $5-9-2010$ & $\begin{array}{l}19.35- \\
20.10\end{array}$ & 35 & $\begin{array}{l}\text { Javier Ruiz Taboa- } \\
\text { da }\end{array}$ \\
\hline 6 & $\begin{array}{l}\text { Cadena } \\
\text { COPE }\end{array}$ & $\begin{array}{l}\text { Tiempo de } \\
\text { Juego }\end{array}$ & $7-9-2010$ & $\begin{array}{l}22.40- \\
23.25 \\
\end{array}$ & 45 & $\begin{array}{l}\text { Pepe Domingo } \\
\text { Castaño }\end{array}$ \\
\hline 7 & $\begin{array}{l}\text { Onda } \\
\text { Cero }\end{array}$ & Radioestadio & $12-9-2010$ & $\begin{array}{l}17.05- \\
17.45\end{array}$ & 40 & $\begin{array}{l}\text { Javier Ruiz Taboa- } \\
\text { da }\end{array}$ \\
\hline 8 & $\begin{array}{l}\text { Cadena } \\
\text { COPE }\end{array}$ & $\begin{array}{l}\text { Tiempo de } \\
\text { Juego }\end{array}$ & $19-9-2010$ & $\begin{array}{l}17.15- \\
17.40\end{array}$ & 25 & $\begin{array}{l}\text { Pepe Domingo } \\
\text { Castaño }\end{array}$ \\
\hline 9 & $\begin{array}{l}\text { Cadena } \\
\text { COPE }\end{array}$ & $\begin{array}{l}\text { Tiempo de } \\
\text { Juego }\end{array}$ & $22-9-2010$ & $\begin{array}{l}23.30- \\
23.55 \\
\end{array}$ & 25 & $\begin{array}{l}\text { Pepe Domingo } \\
\text { Castaño }\end{array}$ \\
\hline 10 & $\begin{array}{l}\text { Radio } \\
\text { Nacional }\end{array}$ & $\begin{array}{l}\text { Tablero Depor- } \\
\text { tivo }\end{array}$ & $25-9-2010$ & $\begin{array}{l}18.50- \\
19.20 \\
\end{array}$ & 30 & \\
\hline 11 & $\begin{array}{l}\text { Punto } \\
\text { Radio }\end{array}$ & $\begin{array}{l}\text { El Mirador de } \\
\text { la Liga }\end{array}$ & $3-10-2010$ & $\begin{array}{l}18.00- \\
18.45\end{array}$ & 45 & $\begin{array}{l}\text { Fernando Martínez } \\
\text { Teruel 'Fernandis- } \\
\text { co' }\end{array}$ \\
\hline 12 & $\begin{array}{l}\text { Cadena } \\
\text { SER }\end{array}$ & $\begin{array}{l}\text { Carrusel De- } \\
\text { portivo }\end{array}$ & $16-10-2010$ & $\begin{array}{l}17.15- \\
17.52 \\
\end{array}$ & 37 & Juanma Ortega \\
\hline 13 & RNE & $\begin{array}{l}\text { Tablero Depor- } \\
\text { tivo }\end{array}$ & $16-10-2010$ & $\begin{array}{l}23.20- \\
23.45 \\
\end{array}$ & 25 & \\
\hline 14 & $\begin{array}{l}\text { Cadena } \\
\text { SER }\end{array}$ & $\begin{array}{l}\text { Carrusel De- } \\
\text { portivo }\end{array}$ & $17-10-2010$ & $\begin{array}{l}17.45- \\
18.20 \\
\end{array}$ & 35 & Juanma Ortega \\
\hline 15 & $\begin{array}{l}\text { Cadena } \\
\text { COPE }\end{array}$ & $\begin{array}{l}\text { Tiempo de } \\
\text { Juego }\end{array}$ & $17-10-2010$ & $\begin{array}{l}21.40- \\
21.53 \\
\end{array}$ & 13 & $\begin{array}{l}\text { Pepe Domingo } \\
\text { Castaño }\end{array}$ \\
\hline 16 & RNE & $\begin{array}{l}\text { Tablero Depor- } \\
\text { tivo }\end{array}$ & $17-10-2010$ & $\begin{array}{l}22.10- \\
22.15\end{array}$ & 15 & \\
\hline 17 & $\begin{array}{l}\text { Cadena } \\
\text { COPE }\end{array}$ & $\begin{array}{l}\text { Tiempo de } \\
\text { Juego }\end{array}$ & $19-10-2010$ & $\begin{array}{l}22.05- \\
22.15 \\
\end{array}$ & 10 & $\begin{array}{l}\text { Pepe Domingo } \\
\text { Castaño }\end{array}$ \\
\hline 18 & $\begin{array}{l}\text { Cadena } \\
\text { SER }\end{array}$ & $\begin{array}{l}\text { Carrusel De- } \\
\text { portivo }\end{array}$ & $19-10-2010$ & $\begin{array}{l}22.25- \\
22.35 \\
\end{array}$ & 10 & Juanma Ortega \\
\hline
\end{tabular}

Fuente: Elaboración propia.

Dado que se pretende analizar la influencia de la figura del animador, se presenta el número de anuncios en los que interviene dicha figura. Pero, antes de eso, se ha hecho una división entre anuncios grabados y los que se realizan en directo des- 
de el estudio. De los 124 anuncios encontrados, 50 se hacen desde el estudio y 74 son grabados (Gráfico 1). Y, posteriormente, para cuantificar la intervención del animador, de entre los 50 anuncios que se hacen in situ se ha realizado una división entre realizados por el «director del programa» (2), el «animador» (48) u «otra persona» (0) (Gráfico 2).

Además, hay que destacar que, de estos 50 anuncios realizados en estudio, en 34 (68\%) se emplean otros elementos sonoros (música, efectos sonoros) y en 32 $(64 \%)$ intervienen las voces de otras personas.

Gráfico 1: Anuncios in situ vs grabados

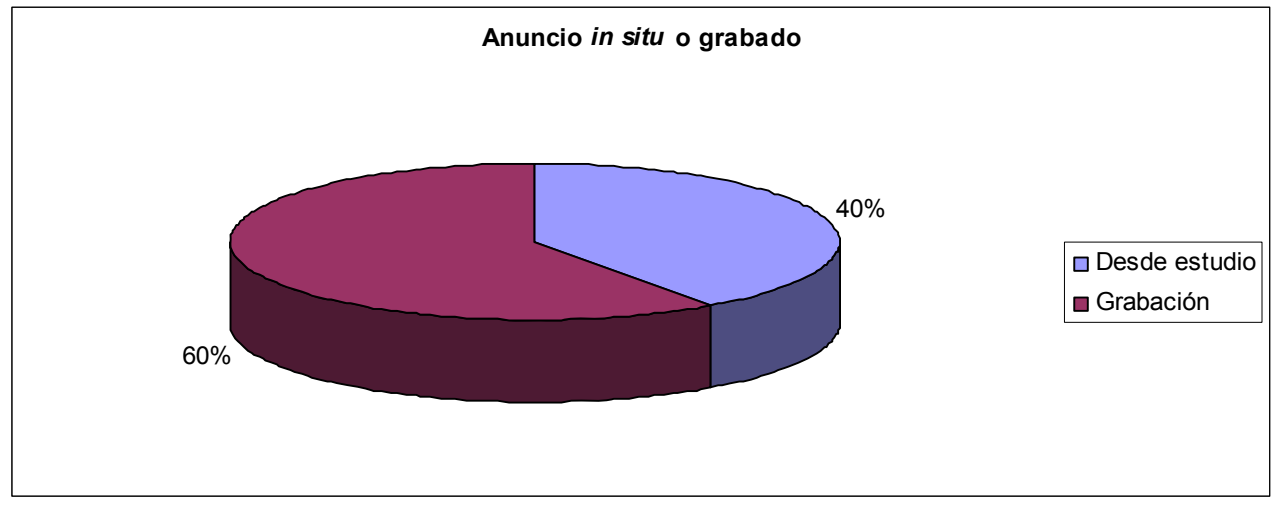

Fuente: Elaboración propia.

Gráfico 2: Anuncios realizados en estudio

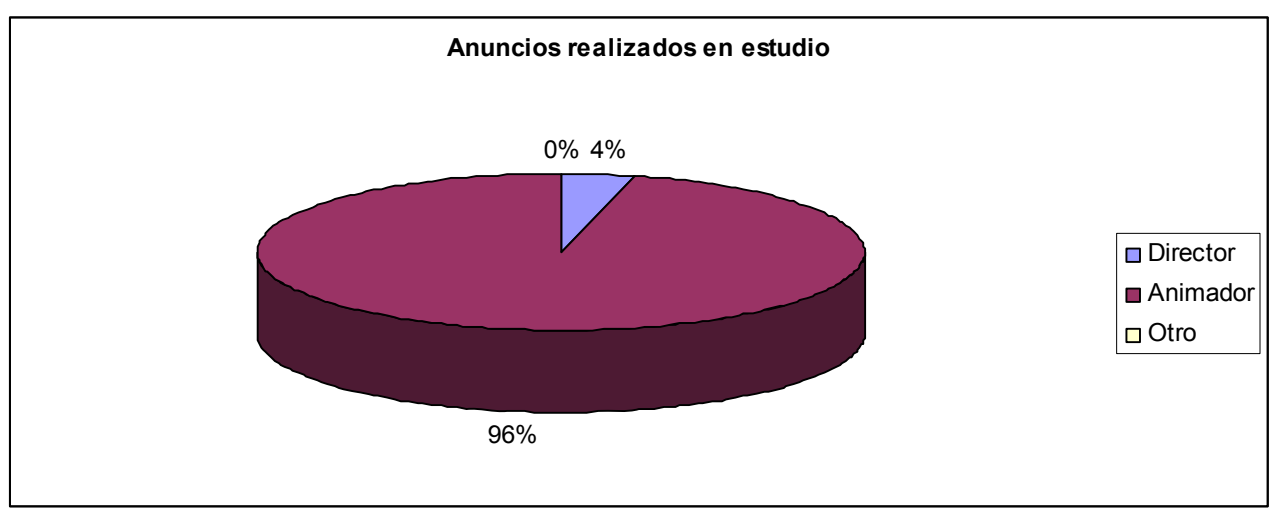

Fuente: Elaboración propia. 
En cuanto a los anuncios que son grabados - un total de 74- se han dividido en subtipos. De los 74 anuncios grabados, se encontraron 55 cuñas, 18 menciones y una careta (Gráfico 3).

Gráfico 3: División de anuncios grabados.

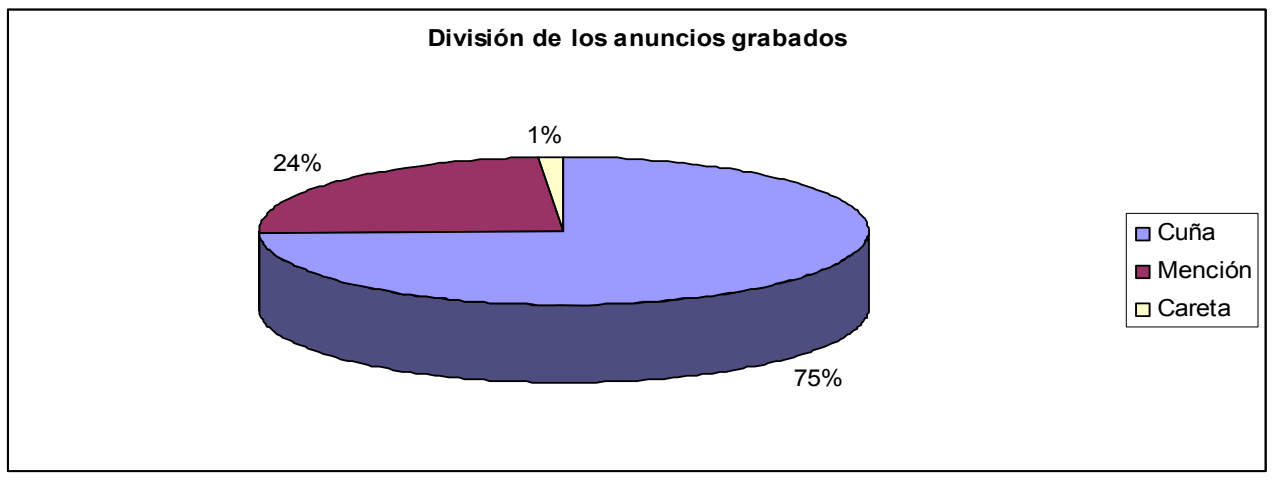

Fuente: Elaboración propia.

En cuanto al tipo de anunciante, se ha realizado una doble división: anuncios ajenos a la emisora o grupo al que pertenece y autopromoción (Gráfico 4). Del total de 124 anuncios analizados, 93 son anuncios externos y 31 de autopromoción.

Gráfico 4: Tipo de anuncio.



Fuente: Elaboración propia.

Por último, en cuanto al tipo de anunciantes -aparte de las autopromociones-, éstos provienen de diversos sectores y al menos se ha encontrado un anuncio de:

- Bancos

- Loterías, apuestas y casas de apuestas (incluidas las de Internet) 
- Grandes superficies comerciales

- $\quad$ Servicios de telefonía (fija y móvil) e Internet

- Periódicos y revistas

- Servicios de televisión

- Productos de comida: lácteos

- Anuncios del Gobierno de España

- Seguros

- Pipas

- Clínicas

- ONG

- Guías de viajes

- Cruceros

- Automóviles: venta de vehículos

- Servicio de reparación de automóviles

- Servicio de luz (energía eléctrica)

- Marcas de productos cárnicos

- Bebidas

- Productos de mejora corporal

- Cromos (colecciones)

- Universidades privadas

En cuanto a la autopromoción, ésta se puede dividir en cuatro subtipos según los anuncios encontrados:

- Autopromoción del propio programa

- Autopromoción de otros programas de la misma emisora

- Autopromoción de otros programas del grupo al que pertenece la emisora

- Autopromoción de otros servicios del grupo

\section{Discusión de los resultados}

Según se aprecia en los resultados de la investigación, el 60\% de los anuncios son previamente grabados mientras que el otro $40 \%$ están realizados in situ y en directo en el estudio. Ello implica que, teóricamente, no se aprecian excesivas diferencias numéricas entre una y otra opción; y más bien esa diferencia se decanta a favor de los anuncios grabados. Asimismo, se observa la importancia del animador en los programas de retransmisiones deportivas radiofónicas. De hecho, de los 50 anuncios que se realizan en directo en el estudio, esta figura interviene en 48 de ellos (lo que supone un 96\%). Tomando como referencia la totalidad de los anuncios analizados, el animador interviene en el $38,71 \%$ de ellos, lo que resalta la importancia de dicha figura en la inserción de publicidad de estos espacios de re- 
transmisiones deportivas. De las cinco emisoras analizadas se encontraron animadores en cuatro de ellas:

Cadena SER: Juanma Ortega

Cadena COPE: Pepe Domingo Castaño

Onda Cero: Javier Ruiz Taboada

Punto Radio: Fernando Martínez Teruel «Fernandisco»

No se encontró la figura del animador en Radio Nacional de España (RNE). Ello se debe a la teórica eliminación de la publicidad del ente RTVE (Ley 8/2009, de 28 de agosto, de financiación de la Corporación de Radio y Televisión Española, publicada en el BOE del 31 de agosto de 2009). Ello no obstante, en Radio Nacional de España sí se han encontrado espacios radiofónicos que pueden entrar dentro del concepto de publicidad, como anuncios del Gobierno de España o autopromoción (mención). Pero esta controversia de la no publicidad en RTVE ya ha sido tratada por otros autores ${ }^{37}$.

Cuando el anuncio es grabado, se observa principalmente la presencia de la cuña publicitaria (en el $75 \%$ de los casos) frente a otras opciones como la mención (24\%). En el caso de la mención, ésta podría asociarse más bien a las autopromociones o publicidades muy concretas (por ejemplo, al iniciarse una ronda de resultados; o antes o después de narrar un gol durante un partido de fútbol). Sólo se encontró una opción diferente: la careta $(1 \%)$.

Por último, en cuanto al tipo de anuncio, llama la atención que existe un alto porcentaje de autopromociones (25\%), dividida en cuatro subtipos, si bien la venta de productos o servicios, ajenos a la emisora, es la base de la publicidad durante los programas que contienen retransmisiones deportivas radiofónicas. Seguramente, a partir de la tipología de anuncios encontrados, se podrían buscar relaciones entre el tipo de anuncio presentado y su principal target group o compradores habituales, aunque esto ya sería más propio de otro estudio.

\section{Conclusiones}

Para concluir, vamos a realizar una valoración de las hipótesis planteadas a partir de los resultados obtenidos. Se acepta la hipótesis 1, al corroborar que la figura del animador juega un papel relevante en los programas que contienen retransmisiones deportivas radiofónicas. Dicha figura está presente en la transmisión de la publicidad aunque su labor se amplía a otras labores dentro del programa (como conductor en determinadas secciones del programa, a través de intervenciones y

37 GutiérReZ, B.; RodríGueZ, M.; Gallego, C.; Herrero, J. (2010): «La publicidad en radio, la no publicidad en TVE, ¿algo a diferenciar?», en Balsebre, A.; Perona, J. J. (eds.): Actas del I Congreso PUBLIRADIO, Icono 14, Revista de Comunicación, Educación y TIC, 4, 337-351, ISSN: 1697-8293. Disponible en Internet en: http://www.icono14.net/files/actas_1congreso_publiradio.pdf. 
opiniones sobre lo que acontece en cada momento en torno a la actualidad deportiva, etc.). De las cinco emisoras analizadas, solamente no se encontró la figura del animador en Radio Nacional de España, por las razones expuestas en la sección anterior.

A pesar de que se destaca la figura del animador, no se puede aceptar la primera parte de la hipótesis 2, que decía que el mayor porcentaje de los anuncios publicitarios en este género radiofónico tiene como base la figura del animador y deja en un segundo plano la cuña publicitaria o similar. Ello se debe a que, si se toma como base la totalidad de anuncios, realmente se encuentran más cuñas (un total de 55) que anuncios realizados por el animador (un total de 48). Por su parte, la segunda parte de la hipótesis 2 -que afirma que cuando el anuncio es grabado, la opción elegida el mayor número de las veces es la cuña- sí es aceptada.

Por último, la tercera de las hipótesis -los principales anuncios de la radio deportiva española tienen que como principal función vender un producto o servicio ajeno a la emisora radiofónica- es igualmente reafirmada aunque llama la atención el gran porcentaje hallado de autopromoción.

Otra conclusión fruto de la observancia, anexa pero que no fue redactada en el apartado de las hipótesis de antemano, es que para que el oyente no desconecte, la radio ha sabido combinar perfectamente programación y publicidad: se integra la publicidad en el contenido «de tal forma que no se llegue a distinguir qué es publicidad y qué es información» ${ }^{38}$.

\subsection{El caso de la cadena COPE en verano de 2010}

La publicidad tratada en este tipo de género queda patente en la enorme importancia y gran espaldarazo que la cadena COPE realizaba en el verano de 2010, contratando a un gran número de profesionales provenientes del programa «Carrusel Deportivo» de la cadena SER -líder de audiencia en lo que a la radio deportiva se refiere- y entre los que se encontraba uno de los animadores radiofónicos más reconocidos en la actualidad: Pepe Domingo Castaño. Esta apuesta ha repercutido en un importante aumento de la publicidad en el programa «Tiempo de Juego» de la cadena COPE.

\subsection{Hacia una definición del animador en radio deportiva}

Aunque es difícil establecer una definición de la figura del animador en los programas radiofónicos que contienen retransmisiones deportivas -lo que más bien pretendemosen el presente trabajo es invitar a reflexionar sobre ello-, sí cabe destacar que este profesional cumple una serie de características que pasan por: 
a) Dar continuidad al programa deportivo y ser un perfecto acompañante del director; más aun si se tiene en cuenta que los principales animadores en este tipo de programa hacen labores más allá de la mera publicidad.

b) Como consecuencia de lo anterior, saber fusionar información y publicidad en un solo mensaje para evitar la huida de oyentes en los minutos publicitarios.

c) Debe jugar con la naturalidad propia de quien "cuenta una historia» y no de «quien trata de vender un producto/servicio», aunque la finalidad sea esta última.

d) Modular su voz para, más allá del discurso literario, combinar las características sonoras para insertar uno u otro tipo de publicidad, teniendo en cuenta variables como el tipo de producto/servicio publicitado y el momento del programa en el que se inserta.

\subsection{Futuras líneas de investigación}

Aunque ya se han venido anunciando con anterioridad, las futuras líneas de investigación pueden girar en torno a:

- La figura del animador en los programas basados en las retransmisiones deportivas en radio es de las más importantes en la radio española. Esto se puede lograr aplicando la metodología a otro tipo de programas deportivos: como ejemplo, cada vez es más frecuente la presencia de anuncios realizados en directo en los magazines deportivos que comienzan en la medianoche (como «El Larguero», en la cadena SER, o «El Partido de las 12», en la cadena COPE). También se puede comparar dicha figura con otras emisiones nacionales, regionales, locales... y con programas no deportivos que permitan establecer diferencias entre uno y otro tipo de programa.

- Los resultados de la presente investigación son en términos generales y ahora se puede continuar trabajando para poder establecer los criterios que utilizan unas $u$ otras emisoras con respecto a la utilización de la cuña o la preferencia por el animador. Futuros estudios permitirán seguir conociendo más en profundidad este tipo de asuntos, y la utilización de tablas de contingencia -y resultados puestos en paralelo cuando las muestras sean más amplias- permitirán establecer semejanzas y diferencias entre la publicidad de unas y otras emisoras. Incluso, como en la línea anteriormente propuesta, se puede proponer ampliar el objeto de estudio, para que los resultados resulten aplicables más allá de las emisoras puramente generalistas.

\section{Referencias bibliográficas}

ASOCIACIÓN PARA LA INVESTIGACIÓN DE LOS MEDIOS DE COMUNICACIÓN: Estudio General de Medios (resumen de abril de 2009 a marzo de 2010). Disponible en: $\mathrm{http}: / /$ www.aimc.es/aimc.php

BALSEBre, A. (2002): Historia de la radio en España (v. II), Madrid, Cátedra.

- (1994): El lenguaje radiofónico, Madrid, Cátedra. 
Balsebre, A.; Ricarte, J. M.; Perona, J. J.; Roca, D.; Barbeito, M. L Fajula, A. (2006): Los mitos de la publicidad radiofónica. Estrategias de la comunicación publicitaria en la radio española, Madrid, Cátedra.

BONET, M. (2005): «La radio española 1994 - 2004. Una década de consolidación y desencanto», Sphera Pública, 5. Disponible en: https://docs.google.com/viewer?url=http: //www.ucam.edu/sphera/numeros/numero-5/sphera5.pdf

Castaño, P. D. (2006): Carrusel Deportivo: diario de un año, Madrid, Santillana Ediciones Generales.

CASTAÑÓN Rodríguez, J. (2009): «Recursos lingüísticos en la radio deportiva», Idioma y deporte [en línea], 108. Disponible en http://www.idiomaydeporte.com/radiorec.htm.

EL PAÍs, martes, 6 de julio de 2010.

FAJUlA, A. Y BARBEITO, M. L. (2005): «La radio publicitaria. El peso del inmovilismo», Quaderns del CAC, 22, 49-62. Disponible en http://www.audiovisualcat.net/publicaciones/Q22casbarbeitofajula.pdf

GonZÁlez CONDE, J. (2008): «La publicidad como género radiofónico», en Alcudia, M. (coord.): Nuevas perspectivas sobre los géneros radiofónicos, Madrid, Fragua, 148-191.

GUARINOS, V. (2000): «Géneros publicitarios y radiofónicos: últimas tendencias», Questiones Publicitarias, 8, 26-35. Disponible en http://www.maecei.es/pdf/n8/articulos/generos publicitarios radiofonicos ultimas tendencias.pdf

Gutiérrez, B.; RoDríguez, M.; Gallego, C.; Herrero, J. (2010): «La publicidad en radio, la no publicidad en TVE, ¿algo a diferenciar?», en Balsebre, A.; Perona, J. J. (eds.): Actas del I Congreso PUBLIRADIO. Icono 14, Revista de Comunicación, Educación y TIC, 4, 337-351. Disponible en: http://www.icono14.net/files/actas 1 congreso_publiradio.pdf

HERRERO GUTIÉRREZ, F. J.; RODRÍGUEZ RAMOS, D. (2009): «La locución de los narradores deportivos radiofónicos en España«», Revista Latina de Comunicación Social, 64, 968 a 987, La Laguna (Tenerife): Universidad de La Laguna, recuperado el 4 de octubre de 2010 de http://www.revistalatinacs.org/09/art/874_Salamanca/75_101_Herrero.html DOI: 10.4185/RLCS-64-2009-874-968-987.

IgARTUA, J. J. (2006): Métodos cuantitativos de investigación en comunicación, Barcelona, Bosch.

LEY 8/2009, de 28 de agosto, de financiación de la Corporación de Radio y Televisión Española.

MALVAR, L. (2005): La radio deportiva en España: 1927-2004, Madrid, Pearson Alhambra y Marca.

ORTIZ, M. A.; Volpini, F. (1995): Diseño de programas en radio: guiones, géneros y fórmulas, Barcelona, Paidós Ibérica.

PÁGINA WEB: www.frecuenciadigital.es (para recopilación de audiencias EGM) - Última visita: 8 de febrero de 2010 .

— www.rae.es (Real Academia Española) - Última visita: 5 de enero de 2010.

- www.republica.es/2010/12/02/paco-gonzalez-le-roba-300-000-oyentes-a-la-ser/ (Noticia en republica.es sobre la $3^{\text {a }}$ oleada del EGM 2010) - Última visita: 8 de febrero de 2010.

— www.rtve.es (Radio Televisión Española) - Última visita: 17 de enero de 2010. 
- www.rtve.es/rtve/20101202/balance-anual-rne-cierra-2010-como-radio-mas-crecidotercera-posicion-entre-todas-cadenas/379460.shtml (Noticia de RTVE sobre el balance del EGM en 2010) - Última visita: 8 de febrero de 2010.

— http://www.superdeporte.es/polideportivo/2010/12/03/cope-duplica-oyentes-frentedescenso/112891.html (Noticia en Superdeporte.es sobre el EGM) - Última visita: 8 de febrero de 2010.

Perona, J. J.; BARBeito, M. L. (2008): «El lenguaje radiofónico en la publicidad del prime time. Los anuncios en la "radio de las estrellas"》, Telos: Cuadernos de Comunicación e Innovación, 77, 115-124. Disponible en: http://sociedadinformacion.fundacion.telefonica.com/telos/articulodocumento.asp@idarticulo\%3D1\&rev\%3D77.htm

RoDERo, E. (2008): «Publicidad en radio: Publicidad, sí, pero no radiofónica «», Área Abierta, 20, julio. Disponible en: http://revistas.ucm.es/inf/15788393/articulos/ARAB0808230001E.PDF

Rodero, E.; Alonso, C. M.; Fuentes, J. A. (2004): La radio que convence. Manual para creativos y locutores publicitarios, Barcelona, Editorial Ariel.

RIFFE, D.; LACY, S.; FICO, F. G. (1998): Analyzing media messages: using quantitative content analysis in research, Mahwah (New Jersey), Lawrence Erlbaum.

RuIZ Yudego, M. (2002): "Análisis de la comunicación deportiva en radio a través de un programa pionero: Carrusel Deportivo», Proyecto de licenciatura, Universidad Pontificia de Salamanca.

SeIJAS, L. (1996): «La publicidad en radio», Documentos de las Ciencias de la Información, 19, 281-300. Disponible en: http://revistas.ucm.es/inf/02104210/articulos/DCIN9696110281A.PDF. 